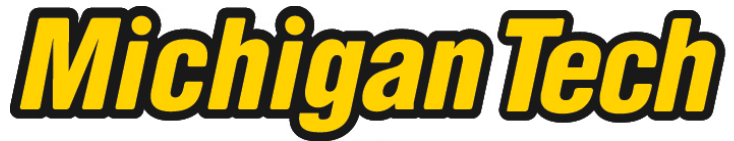 \\ Michigan Technological University Create the Future Digital Commons @ Michigan Tech
}

Dissertations, Master's Theses and Master's Reports - Open

Dissertations, Master's Theses and Master's

Reports

2010

\section{A comparison of ground cover and frequency estimation methods for post-harvest soil monitoring}

Curtis David Kvamme

Michigan Technological University

Follow this and additional works at: https://digitalcommons.mtu.edu/etds

Part of the Forest Sciences Commons

Copyright 2010 Curtis David Kvamme

\section{Recommended Citation}

Kvamme, Curtis David, "A comparison of ground cover and frequency estimation methods for postharvest soil monitoring", Master's Thesis, Michigan Technological University, 2010.

https://doi.org/10.37099/mtu.dc.etds/143

Follow this and additional works at: https://digitalcommons.mtu.edu/etds

8 Part of the Forest Sciences Commons 


\title{
A COMPARISON OF GROUND COVER AND FREQUENCY ESTIMATION METHODS FOR POST-HARVEST SOIL MONITORING
}

\author{
CURTIS D. KVAMME
}

\author{
A THESIS \\ Submitted in partial fulfillment of the requirements for a degree of \\ MASTER OF SCIENCE IN FOREST ECOLOGY AND MANAGEMENT \\ MICHIGAN TECHNOLOGICAL UNIVERSITY \\ 2010
}


This thesis, "A comparison of ground cover and frequency estimation methods for postharvest soil monitoring," is hereby approved in partial fulfillment of the requirements for the Degree of MASTER OF SCIENCE IN FOREST ECOLOGY AND MANAGEMENT.

SCHOOL OF FOREST RESOURCES AND ENVIRONMENTAL SCIENCE

Signatures:

Thesis Advisor

Dr. Martin F. Jurgensen

Dean of School

Dr. Margaret R. Gale

Date 


\section{Acknowledgements}

I owe more thanks to Debbie Page-Dumroese than I can include here, but her guidance and enthusiasm for soils ultimately led me to a career path I was excited about. Thanks also to my advisor, Martin Jurgensen for his close attention and timely feedback, which has been invaluable in completing this thesis. I would also like to thank James Pickens for his patience and clarity in many meetings to discuss statistics, and Janice Glime for her willingness to join and 'save’ my committee at the last minute. I am indebted to Kent Houston on the Shoshone National Forest, and Tommy John at the Forest Service Rocky Mountain Regional office for professional guidance and help developing this project. Huge thanks also go to Michael Dieter and Celeste Governale for field assistance. I also must thank Denise Zitnik, the main reason I’ve been able to get through this process with a smile. And finally, I would like to acknowledge my father; his dedication to me and my brother early in our lives was incredible, and it is something I will always remember, and strive to duplicate. I wish he could have seen me get to where I am today. 


\section{Table of Contents}

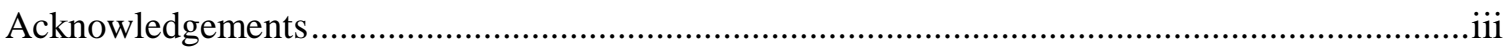

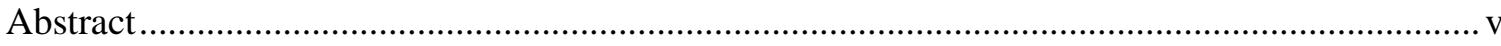

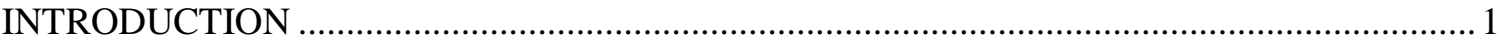

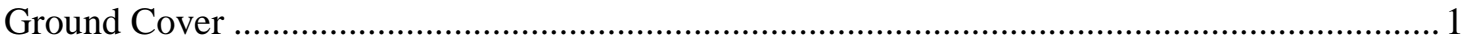



U.S. Forest Service Forest Soil Disturbance Monitoring Protocol ............................................. 5

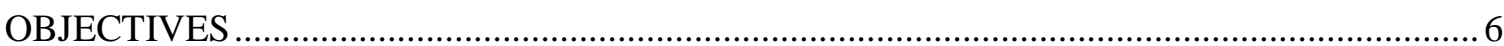

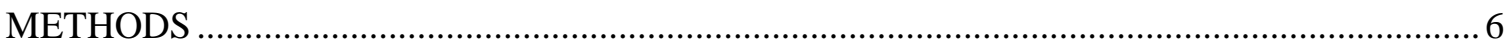

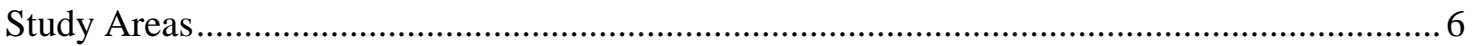

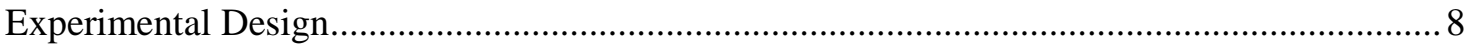

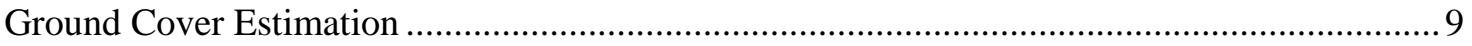

Sampling Time

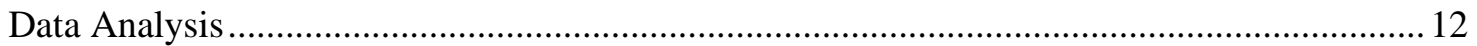

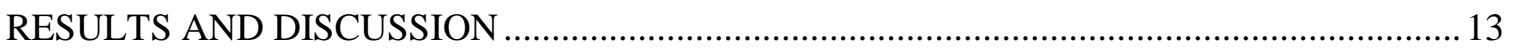

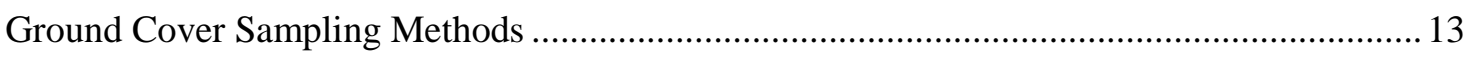

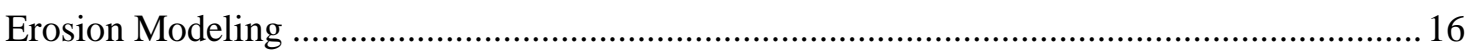

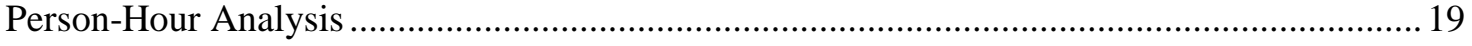

Sampling Implications for Soil Disturbance Monitoring ....................................................... 22

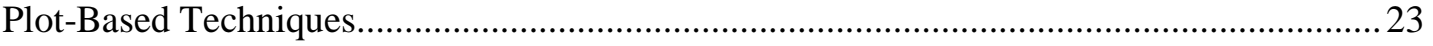

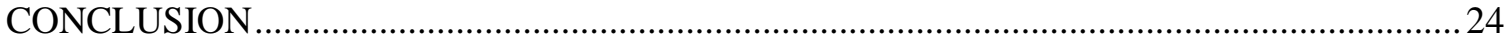

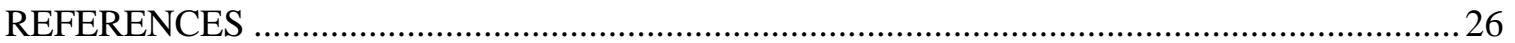




\begin{abstract}
The amount and type of ground cover is an important characteristic to measure when collecting soil disturbance monitoring data after a timber harvest. Estimates of ground cover and bare soil can be used for tracking changes in invasive species, plant growth and regeneration, woody debris loadings, and the risk of surface water runoff and soil erosion. A new method of assessing ground cover and soil disturbance was recently published by the U.S. Forest Service, the Forest Soil Disturbance Monitoring Protocol (FSDMP). This protocol uses the frequency of cover types in small circular $(15 \mathrm{~cm})$ plots to compare ground surface in pre- and post-harvest condition. While both frequency and percent cover are common methods of describing vegetation, frequency has rarely been used to measure ground surface cover. In this study, three methods for assessing ground cover percent (step-point, $15 \mathrm{~cm}$ dia. circular and $1 \mathrm{x} 5 \mathrm{~m}$ visual plot estimates) were compared to the FSDMP frequency method. Results show that the FSDMP method provides significantly higher estimates of ground surface condition for most soil cover types, except coarse wood. The three cover methods had similar estimates for most cover values. The FSDMP method also produced the highest value when bare soil estimates were used to model erosion risk. In a person-hour analysis, estimating ground cover percent in $15 \mathrm{~cm}$ dia. plots required the least sampling time, and provided standard errors similar to the other cover estimates even at low sampling intensities $(\mathrm{n}=18)$. If ground cover estimates are desired in soil monitoring, then a small plot size $(15 \mathrm{~cm}$ dia. circle), or a step-point method can provide a more accurate estimate in less time than the current FSDMP method.
\end{abstract}




\section{INTRODUCTION}

Many studies have shown that timber harvesting and other forest management activities can have major impacts on physical and chemical soil properties (Powers et al., 1990; Jurgensen et al., 1997; Gomez et al., 2002b). Soil compaction, for example, can change soil porosity and water holding capacity to the benefit or detriment of tree growth, depending on soil and site conditions (Youngberg, 1959; Gomez et al., 2002b; Heninger et al., 2002;). Compaction can also reduce water infiltration, thereby increasing runoff and erosion (Edwards and Burney, 1991). Soil erosion, while often not a significant natural disturbance in forested settings, can be increased by some timber management activities; often forest road networks are the largest sources of sediment (Elliot et al., 1998; Rice et al., 1999). Depending on the level of impact and the extent of soil cover removed, timber harvest areas can also become sources of sediment, especially on skid trails where ground cover can be reduced up to 90\%, or on slopes >35\% (Packer, 1967; Swanson et al., 1989; Robichaud et al., 1993; Elliot et al., 1998). Because ground cover is an important erosion-controlling factor and is often removed by ground-based timber harvesting equipment, it is important to monitor how it changes after harvesting.

\section{Ground Cover}

Ground surface cover components (vegetation litter, woody debris, rocks, living plants, mineral soil) provide information about invasive species, plant growth and regeneration, woody debris loadings, and surface organic layers (Jurgensen et al., 1997; Elzinga et al., 1998; Woldendorp et al., 2004). Detection of ground cover changes after 
management activities are important, since exposed soil at some sites has a large role in determining erosion risk (Lang, 1979). Many studies have used simulated rainfall (Simanton et al., 1991), or sediment trap experiments (Larsen et al., 2009) to show that extent of bare soil has a greater influence on erosion than vegetation canopy cover, soil water repellency, and soil sealing. Therefore, it is important to measure bare soil and ground cover after timber management activities to assess erosion risk. While erosion may not occur immediately after a timber harvest even with reduced soil cover, the possibility of increased erosion on a site remains until ground cover and vegetation have reestablished (Packer, 1967; Swanson et al., 1989; Robichaud et al., 1993). However, the amount of ground cover needed to limit erosion risk varies by site and soil type, so regulatory standards are often very broad. For example, some U.S. Forest Service Soil Quality Standards only require that ground cover be sufficient to prevent erosion from exceeding natural rates (Elliot et al., 1998; Page-Dumroese et al., 2000).

Erosion models are commonly used to estimate current or changed erosion rates resulting from timber harvesting (Merritt et al., 2003). Several models available today, such as the U.S. Forest Service Disturbed Water Erosion Prediction Project (FSWEPP), can predict soil erosion based on a set of input variables, which includes an estimate of ground cover (Elliot et al., 2000; Merritt et al., 2003). Consequently, an accurate estimate of ground cover, combined with an erosion model, is one of the most efficient ways to predict the risk of future erosion resulting from management activities. 


\section{Soil Monitoring Protocols}

Soil disturbance monitoring is one way to estimate bare soil surface and erosion risk, and if pre-harvest baseline data are collected, it is possible to estimate whether increased erosion risk resulted from timber management activities. Soil monitoring is also useful and sometimes required on public lands in the U.S. to show that local and federal regulations for water quality, soil quality, and timber management are being met. Environmental standards used by the U.S. Forest Service are partly defined by the Multiple Use and Sustained Yield Act of 1960, the National Environmental Policy Act of 1969, the National Forest Management Act of 1976, and others. Additionally, each U.S. Forest Service Region has standards dictating the levels of disturbance types thought to influence long-term sustainability or soil quality; this includes a minimum percent ground cover that is acceptable after a harvesting activity (Powers et al., 1998; Page-Dumroese et al., 2000). It is not clear that the broad standards outlined by each U.S. Forest Service region actually relate to severe or detrimental levels of soil disturbance that impair vegetative growth or hydrologic function (Burger and Kelting, 1998; Page-Dumroese et al., 2000). However, as long as quantitative, spatial, or qualitative (e.g. erosion presence) requirements are mandated, soil monitoring methods must be capable of consistently detecting differences in soil cover and other disturbances from pre- to post-harvest.

There are at least three methods that can be used to assess soil disturbance after timber harvesting in the western United States. These different methods, discussed by Curran et al. (2007), were developed by the U.S. Forest Service, Weyerhaeuser Timber Company, and the British Columbia Ministry of Forests (respectively: Page-Dumroese et 
al., 2009a,b; Scott et al., 1979, as referenced in Heninger et al., 2002; and B.C. Ministry of Forests, 2001). Only the U.S. Forest Service and the B.C. Ministry of Forests methods provide a quantitative measure of ground cover or bare soil, because it is considered important for changes in hydrologic function.

Ground cover is usually recorded as area covered by each cover type (e.g. litter, plant, etc.), and is commonly estimated by: 1) visual estimation of percent cover in a plot frame, 2) counting the proportion of points along a transect covered by each type, or 3) by measuring the proportion of distance covered by cover types along a line (Elzinga et al., 1998). Other metrics besides percent cover can be used to describe aboveground vegetation attributes, such as density of plants per unit area, or the frequency of a plant species occurring within a number of plot samples (Greig-Smith, 1983; Elzinga et al., 1998). These other measures are often used to approximate or replace a 'true' cover estimate for vegetation canopies, because they are often faster and easier to collect than percent cover (Elzinga et al., 1998). Frequency, in particular is much faster than visual cover estimates of plant canopy, because only presence or absence of each cover type is recorded. Speed and efficiency of a monitoring method is important for any resource manager, because less sampling time reduces monitoring cost. However, frequency is seldom used for assessing ground surface (Elzinga et al., 1998), and it is not clear if frequency is more efficient than percent cover methods for assessing ground surface condition. 


\section{U.S. Forest Service Forest Soil Disturbance Monitoring Protocol}

The Forest Soil Disturbance Monitoring Protocol (FSDMP) has become a popular tool among U.S. Forest Service soil scientists to monitor soil disturbance after timber harvesting (Page-Dumroese et al., 2009a, b). It provides a consistent, well-defined tool to collect information about soil in pre- and post-harvest condition. In this protocol, ground cover is assessed by recording the presence or absence of seven ground cover types (bare soil, litter, rock, fine wood, coarse wood, live plant, and invasive plant) in measured plots (15cm diameter circle) along a random transect. These cover-type data are used mostly to determine erosion risk within a sampled area. Since this protocol is being widely used, and data can be shared among National Forests and Regions in the U.S., it is important to ensure that ground cover monitoring objectives can be met, and that methods used in this protocol are supplying useful data.

The FSDMP method uses a measure of frequency, not percent cover, to assess ground surface cover. As mentioned before, frequency data can be collected very quickly, however, the values of these data depend on the plot size used, and the size and shape of measured cover types. With very small plot sizes (3/4 inch diameter), frequency values are generally close to plant canopy cover estimates (Hutchings and Holmgren, 1959). However, larger plot sizes tend to increase the frequency of measured plant canopies (Elzinga et al., 1998). The 15cm diameter circle plot used in the FSDMP is not a common size for measuring vegetation canopies or ground cover (Elzinga et al., 1998). To my knowledge, no assessment has been done to determine if frequency data from this plot size can be used to accurately estimate ground cover in the field. 


\section{OBJECTIVES}

The objectives of my study are to: 1) compare the FSDMP ground frequency estimation method to three ground cover methods (step-point, 15cm dia. and 1x5m plots), 2) determine the time required by each method to collect data at two levels of sampling intensity, and 3) evaluate the usefulness of each method for modeling erosion risk with FSWEPP.

\section{METHODS}

\section{Study Areas}

Study sites are located on the Shoshone National Forest in northwestern Wyoming (Figure 1). Three recently active timber sales were selected on the forest; all sites had similar silvicultural prescriptions (sanitation-salvage) resulting from insect infestation or beetle kill. Other site characteristics are given in Table 1. The Carter Mountain site had heavy infestations of spruce beetle and mountain pine beetle, and the Deadman Bench sale had moderate spruce beetle and Douglas-fir beetle infestations. Both sites were treated in 2006-2007 with Leave Tree Mark (LTM) thinning techniques to remove dead and dying timber.

The Purdy Salvage area also had severe mountain pine beetle and spruce beetle infestations, but was also burned by a wildfire in August and September 2006. The applied thinning technique varied, depending on the severity of fire and/or insect damage, thus the cutting units sampled for this study contained multiple harvest treatment types. A majority of the area was either treated with a group selection or clearcut with reserves 
in 2008-2009. However, different harvesting treatments on this site resulted in a similar number of equipment passes during harvest operations, and similar overall post-harvest tree density as the other two study areas (personal communication, R. Spiering, 2009). Engelmann spruce (Picea engelmannii Parry ex Engelm. var. engelmannii) was one of the dominant overstory trees at all three sites. Lodgepole pine (Pinus contorta Douglas ex Louden var. latifolia Engelm. ex S. Watson) was codominant on the Purdy and Carter sites, while the Deadman site contained Douglas-fir (Pseudotsuga menziesii (Mirb.) Franco var. glauca (Beissn.) Franco) and a minor component of lodgepole pine. Soils at each site were classified using Soil Taxonomy (Soil Survey Staff, 2003):

Deadman Bench- loamy skeletal, mixed, superactive, Eutric Haplocryalf; Carter Mountain- loamy-skeletal, mixed, superactive, Typic Eutrocryept; and Purdy- loamyskeletal, mixed, superactive, Typic Haplocryalf.

Table 1. Physical site characteristics for study areas.

\begin{tabular}{ccccccc} 
Timber Sale & Slope (\%) & $\begin{array}{c}\text { Aspect } \\
\text { Range }\end{array}$ & Elevation (m) & Parent Material & $\begin{array}{c}\text { Surface Soil } \\
\text { Texture }\end{array}$ & $\begin{array}{c}\text { Study Area } \\
\text { Size (ha) }\end{array}$ \\
\hline $\begin{array}{c}\text { Carter } \\
\text { Salvage }\end{array}$ & $0-30$ & N - NE & $2,600-2,800$ & $\begin{array}{c}\text { Mixed Clastic \& } \\
\text { Volcanic From } \\
\text { Lands lide }\end{array}$ & $\begin{array}{c}\text { Loam - Sandy } \\
\text { Loam }\end{array}$ & 82 \\
\hline $\begin{array}{c}\text { Deadman } \\
\text { Bench }\end{array}$ & $0-35$ & NE - NW & $2,100-2,200$ & $\begin{array}{c}\text { Shale, Limestone \& } \\
\text { Sandstone }\end{array}$ & $\begin{array}{c}\text { Loam - Silt } \\
\text { Loam }\end{array}$ & 145 \\
\hline Purdy & $0-40$ & N- NW & $2,700-2,800$ & $\begin{array}{c}\text { Mixed Clastic \& } \\
\text { Volcanic }\end{array}$ & Loam & 112
\end{tabular}




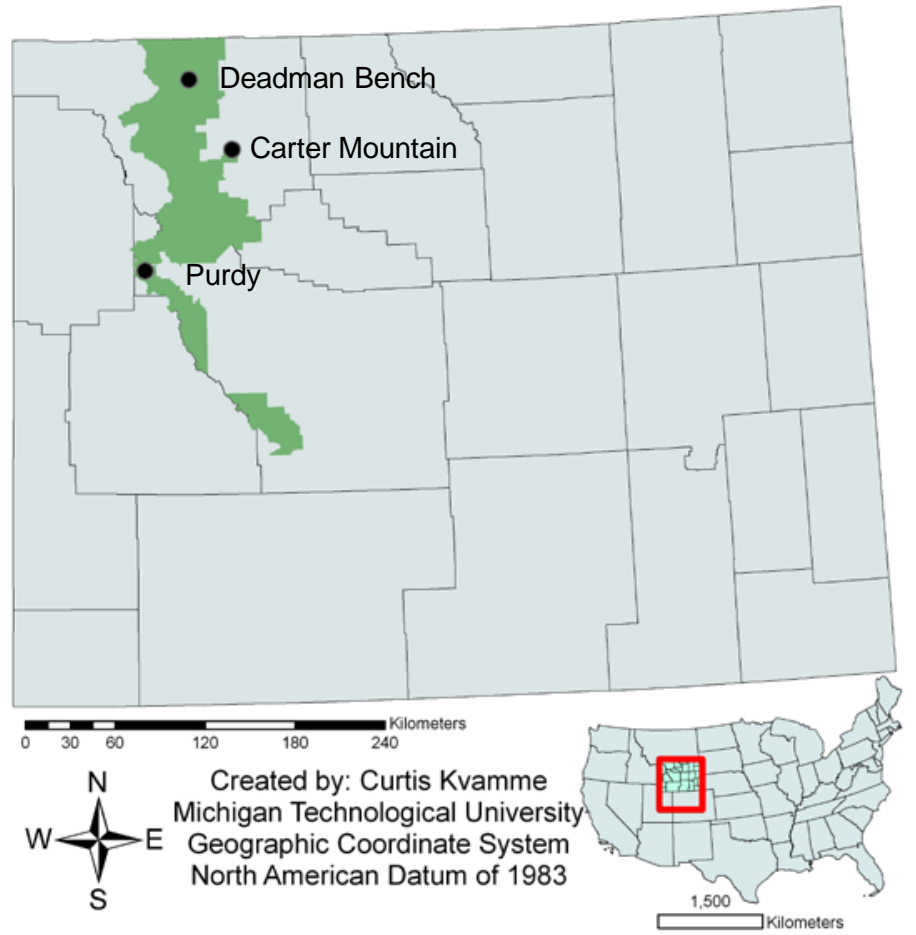

Figure 1. Study site locations, Shoshone National Forest, WY.

\section{Experimental Design}

The sample design described in the FSDMP was used in this study (Page-

Dumroese et al., 2009a). Field sampling occurred in summer 2009, with pilot sampling in summer 2008. A systematic point-line transect method with random starting location and azimuth was used to assess ground cover within four marked cutting units, or four replicates at each site (Figure 2). The replicates consisted of three post-harvested units and one undisturbed control unit. Points along the transect were spaced according to cutting unit size, with larger units having greater point spacing. At each sample point along the transect, I collected ground cover frequency in a 15cm dia. circle (FSDMP method), and the following cover percent methods: step-point, and ocular estimates in plot sizes of $15 \mathrm{~cm}$ dia. and 1x5m (Figure 2). 


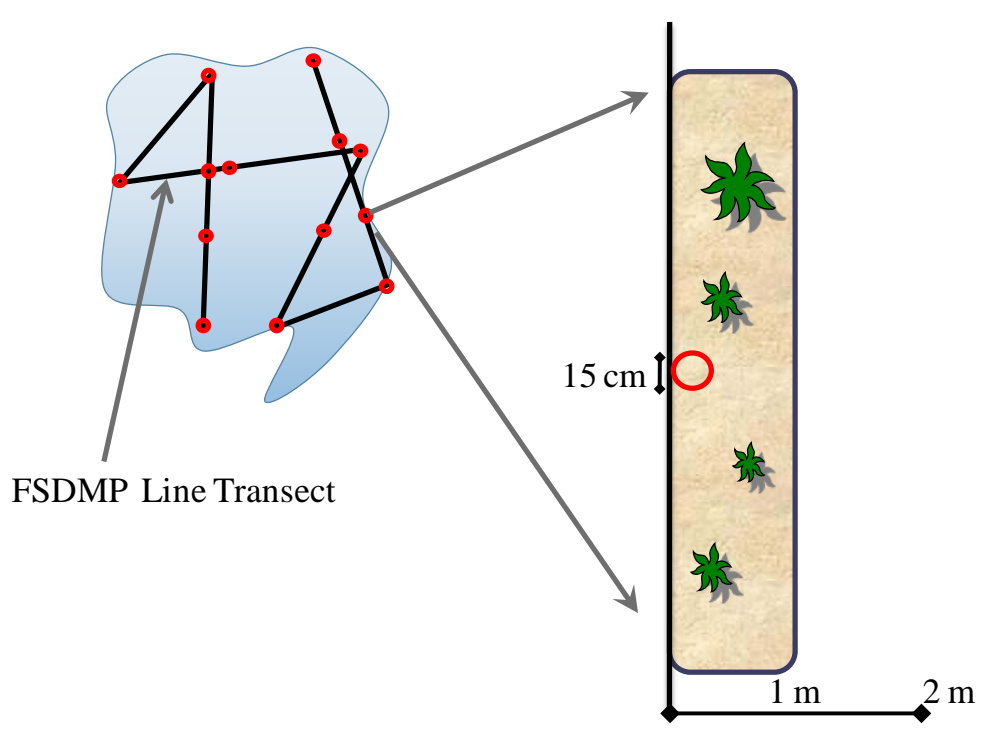

Figure 2. A diagram of the systematic point-line transect used in the FSDMP. The enlarged area shows the $15 \mathrm{~cm}$ diameter circle, and $1 \mathrm{x} 5 \mathrm{~m}$ ocular cover estimation plots. The line on the left represents the sampling transect, which defines the left side for both plots.

\section{Ground Cover Estimation}

The FSDMP method in this study estimated the presence or absence of six ground cover types, bare soil, rock, fine wood, coarse wood, live plant, and litter as they occurred in a $15 \mathrm{~cm}$ circular area around the sampling point (Figure 3). Invasive plant coverage, which is normally assessed in the FSDMP, was not measured. This yields binary presence/absence information for each cover type, where a “1” represents any present cover type, and a "0" represents an absent type. Since this method is used in the monitoring protocol, it was the baseline to which the other three ground cover methods were compared.

Unlike the FSDMP, which records all ground cover types, the step-point transect method records a single value for ground cover at each sample point along the transect. 
In this method, measurements were taken at a "true" point, indicated by an ' $x$ ' in Figure 3, by placing a metal pin flag with a $1.8 \mathrm{~mm}$ tip at the front tip of the observer's boot. The appropriate sample size ( $n$ ) for the FSDMP and step-point methods was calculated from 2008 pilot data with the following equation (Triola, 2001):

$$
n=\frac{\left(z_{\alpha / 2}\right)^{2} * \hat{p} * \hat{q}}{w^{2}}
$$

where $\mathrm{Z}_{\alpha / 2}$ is the table $\mathrm{Z}$-score value determined by the selected level of confidence (1.282 with $80 \% \mathrm{CI}) ; \hat{p}$ is the proportion recorded 'present' for the most variable cover type; $\hat{q}$ is the proportion of points recorded as 'absent' for the determining cover type; and $w$ is $1 / 2$ of the selected margin of error that defines the confidence interval around the mean $(w=.05)$.

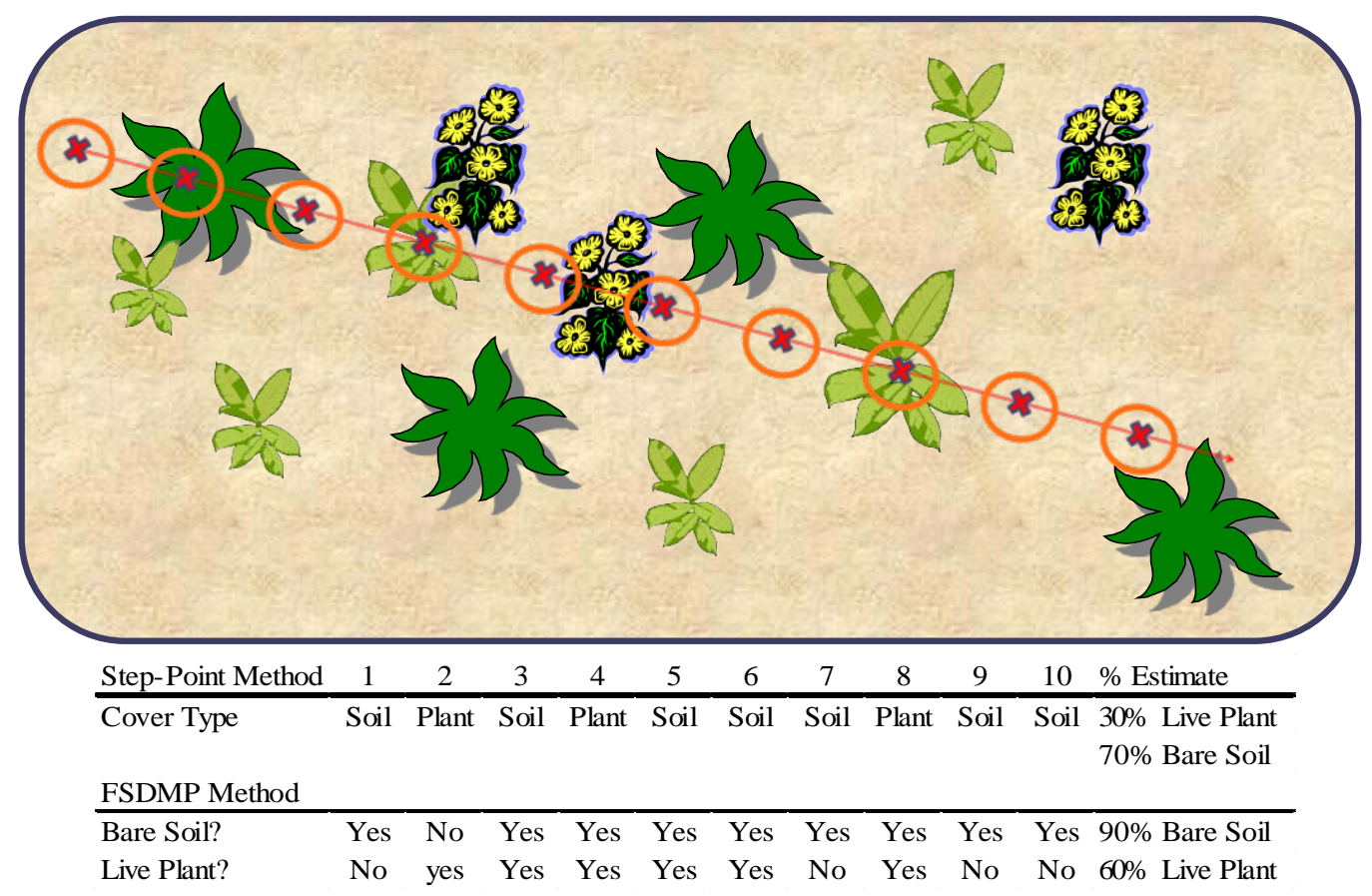

Figure 3. Example of Step-Point (x) and FSDMP (circle) ground cover assessments. The accompanying data table shows a simplified version of data collected, using only two cover types. 
The Daubenmire method (1959) was used to give ocular estimates of percent ground cover on two different plot sizes: a 1x5m rectangle, and a $15 \mathrm{~cm}$ diameter circle (Figure 2). In each plot size, six ground cover types (bare soil, live plant, litter, fine wood, coarse wood, and rock) were estimated by cover classes (Table 2). The sample size (n) for both plot sizes was also calculated from pilot data from 2008 with the following equation (Scheaffer et al., 2006):

$$
n=\frac{N \sigma^{2}}{(N-1) D+\sigma^{2}}
$$

Where:

$$
D=\frac{B^{2}}{4}
$$

$\mathrm{N}$ is the potential number of plots in the population, and $B$ is a two standard-deviation bound on the mean percent bare soil cover within a study site. $B$ was calculated from 2008 pilot data, and was not constant at all sites (Purdy, $B \approx 10.6$; Carter Mt., $B \approx 5.5$; Deadman, $B \approx 1.8$ ). Both plot types were measured at a subset of the total number of points along the transect with a systematic method.

Table 2. Percent classes for plot estimates of ground cover.

\begin{tabular}{cc} 
Cover Class & \% Cover \\
\hline 1 & $0-5$ \\
2 & $6-25$ \\
3 & $26-50$ \\
4 & $51-75$ \\
5 & $76-95$ \\
6 & $96-100$
\end{tabular}




\section{Sampling Time}

In one replicate at each site, the amount of time required to collect data with each of the four methods was recorded in order to perform a person-hour analysis. At every sampling location, a stopwatch was used to record the time spent preparing the site (i.e. setting up sampling plot frame), and assessing ground cover. Since all methods were collected along the same paced transect, the time spent walking between the points was not measured, as it was assumed to be the same for each sampling method.

\section{Data Analysis}

An analysis of variance (ANOVA) procedure was performed with SAS software (Version 9.2). Proportions of ground cover and frequency were transformed with an arcsin square root function to satisfy the ANOVA assumption of homogeneous variability (Steel et al., 1996). Tests for significant differences in mean ground cover estimates among the four methods were performed with Tukey's studentized range test. Additional analyses were performed when significant differences were found between bare soil frequency and percent cover. Estimates of total ground cover from the four methods were used to model potential water erosion on each site using the Disturbed Water Erosion Prediction Project (Disturbed WEPP Model Version 2008.907). The input variables required by the WEPP model include climate, slope, soil texture, and ground cover, and were selected to match site conditions as closely as possible. The FSWEPP model was selected because it is widely used by U.S. Forest Service mangers, has a simple internet interface, and all input variables except ground cover could be held 
constant during model runs. Based on recommendations from the FSWEPP technical documentation, two different 'treatments' (i.e. vegetation or cover types after harvesting) were selected for each site to show a range of potential erosion rates that would be produced using estimated bare soil cover from each method.

\section{RESULTS AND DISCUSSION}

\section{Ground Cover Sampling Methods}

Estimates of cover type by the FSDMP were significantly higher $(\alpha=.05)$ than the other estimation methods, except for coarse wood (Figure 4). While none of the four methods can be said to exactly represent 'true' ground cover, the close agreement of the three cover percent methods for most cover types indicate they provide a consistent and better estimate of ground cover than the FSDMP method (Floyd and Anderson, 1987). The $15 \mathrm{~cm}$ dia. frequency plot used in the FSDMP overestimates percent ground cover, except for coarse wood. This resulted from measuring overlapping layers of ground cover in the FSDMP, while the percent cover methods record a single layer at a point or plot. Frequency methods have also been shown to overestimate plant canopy percent cover with a 3/4 inch plot size (Hutchings and Holmgren, 1959).

In the ANOVA analysis, two significant interactions were found in the FSDMP frequency data (Figure 5) that highlight a problem of frequency methods that makes them difficult to interpret biologically. Frequency data, unlike percent cover, cannot consistently detect seasonal or site changes in cover structural pattern or density (GreigSmith, 1983; Elzinga et al., 1998). For example, Figure 5B shows that the low estimates of bare soil cover at the Deadman site were similar with frequency and cover methods. 

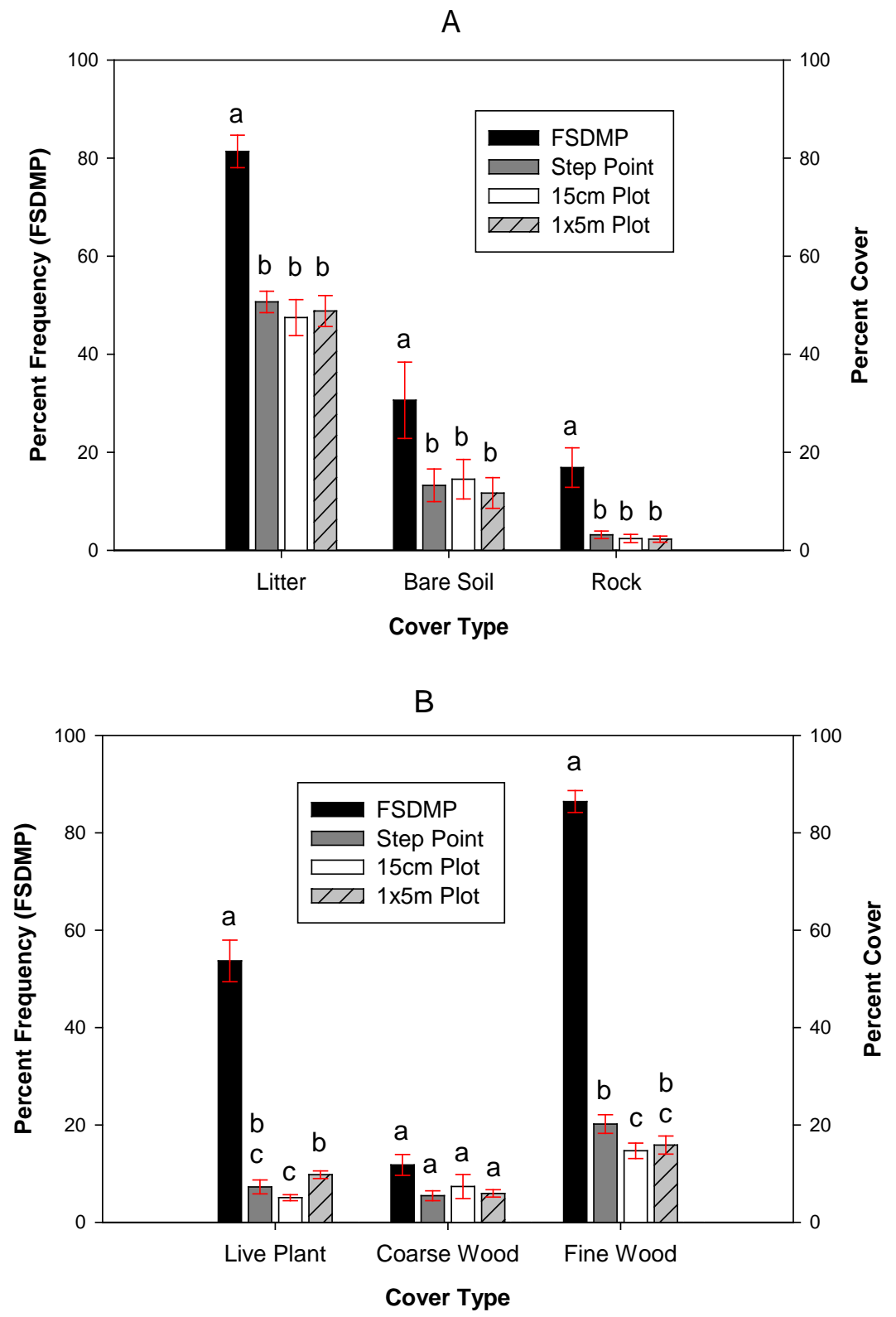

Figure 4. Average estimates of six ground cover types using four sampling methods. Different letters indicate significant differences among sampling methods ( $\alpha=.05$ ); red bars represent one standard error.

However, as the percent of bare soil increased at Purdy and Carter Mountain, the amount of overestimation by the FSDMP increased because small patches of bare soil were more common at these sites. In a frequency plot method, small patches of cover types are 
recorded the same as large continuous patches, so the cumulative effect is a large overestimate of percent cover. A different pattern in live plant cover is displayed in figure 5A, with the largest overestimate occurring at the Carter Mt. site. This inconsistent overestimation of ground cover type greatly reduces the utility of the FSDMP in comparing ground cover percentage from different sites.

Ground cover estimates of the two area plot methods and the step-point method were not significantly different, except for fine wood and live plant covers (Figure 4). In all cases, however, differences among these methods were much smaller than the difference between the FSDMP method, and there was no clear trend showing one cover method consistently had higher or lower estimates of cover types. When the FSDMP data were removed from the analysis, there were no significant interactions between sampling method and study site. Since cover estimates are not biased by changes in cover-type structure, percent cover is more useful for comparing ground surface monitoring data among sites than frequency (Greig-Smith, 1983).

A

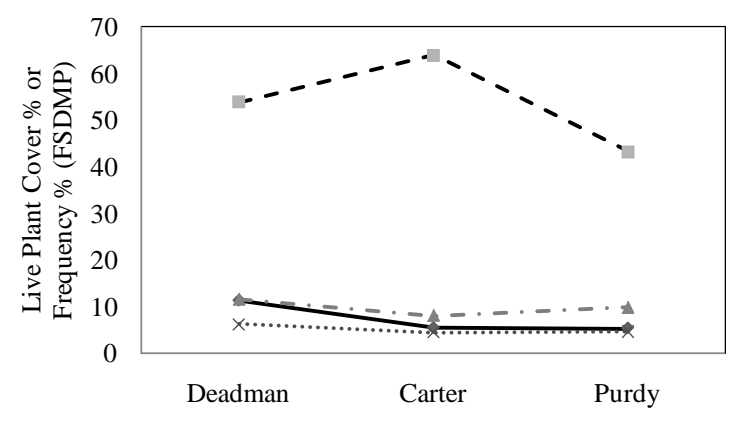

- - Step Point --- FSDMP - $1 \cdot 1 \times 5 \mathrm{~m}$ Plot $\cdots \times \cdot 15 \mathrm{~cm}$ Plot

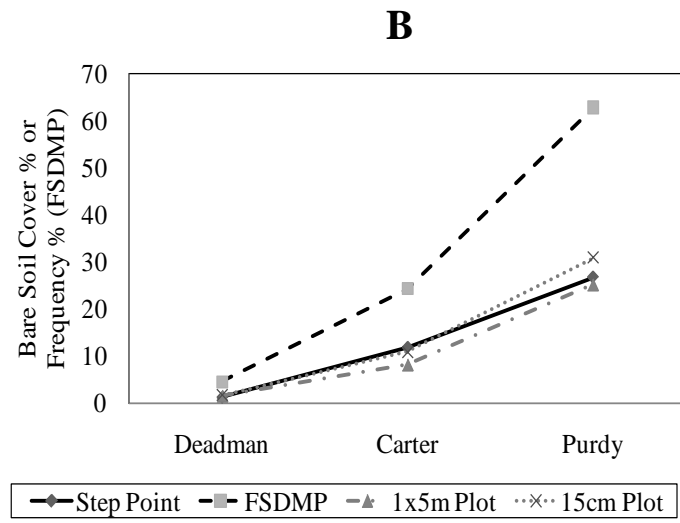

- - Step Point - - FSDMP - -1 1x5m Plot $\cdots * \cdots 15 \mathrm{~cm}$ Plot

Figure 5. Graphs of significant variable interactions between the FSDMP method and sample site, from ANOVA comparison. A) live plant cover data, B) bare soil data. 
There are several important implications for having accurate site-specific estimates of ground cover. For example, pre- and post-harvest surveys are often performed to collect information about the cover and biomass of woody residue of various size and decay conditions, which is important for both nutrient cycling and fire risk management (Laiho and Prescott, 2004 ; Ottmar et al., 2007). While this detailed information is not available from the cover data obtained in this study, percent cover of woody debris and forest floor depth measurements can be used to improve estimates of woody biomass and size classes from woody residue photo series guides (e.g. Maxwell and Wayne, 1980). These photo series contain images of forests with known amounts and percent area covered by woody residue that can be used to estimate site conditions. Additionally, the current version of the FSDMP includes 'invasive plant' as a cover type. Though it was not used in this study, managers could use these data to monitor the spread of known populations, or to initially detect isolated occurrences of invasive or non-native plant species. Finally, obtaining accurate bare soil estimates can be important for other management purposes, such as predicting soil erosion.

\section{Erosion Modeling}

At the Deadman site, less than 2\% difference in predicted erosion was found when FSDMP and percent estimates of bare soil coverage were used as inputs to the Disturbed FSWEPP model. Summarized results for predicted erosion at the other two sites are shown in Figure 6. The control site at Carter Mountain (Figure 6A) also showed no difference in modeled predictions of erosion risk, as the estimates of low bare soil coverage by FSDMP frequency and percent cover methods were very similar. These 
sites generally had low slope steepness, so were not likely to have significant predictions of erosion in FSWEPP.

Since the remaining sites at Purdy and Carter Mountain had higher bare soil coverage, the FSDMP produced higher levels of predicted soil erosion than the percent cover methods (Figure 6). The vegetation conditions shown in the figure are model input parameters (called 'treatment' in FSWEPP) that theoretically represent the conditions at different points of time after harvest; two are shown for each study area to show a likely range of possible model outputs (Elliot, 2000). In Figure 6, the treatments on the right side best represent the conditions at Carter and Purdy (tall grass, and low-severity fire, respectively) in the year each area was sampled. The left side of each figure theoretically represents better established vegetation (shrub and short grass) at each site at least one year after the sampling date. Erosion rates for the control replicate at Purdy (Figure 6B) are likely higher because the treatment units received woody material additions from the timber harvest, which slightly decreased percent exposed bare soil estimates with all methods. The trend of higher erosion predictions with FSDMP data holds for all of the displayed FSWEPP scenarios, but the difference is less in the shrub (Carter Mt.) and short grass (Purdy) treatments.

Overall, differences in erosion prediction only occurred at sites where the natural risk of erosion was high (due to exposed soil and steep slopes), and differences in bare soil estimates between FSDMP and the three percent cover methods was more than $10 \%$. Thus, it seems that the use of either cover or FSDMP frequency data is only important for predicting erosion on sites that have a relatively high natural risk of erosion. 
A
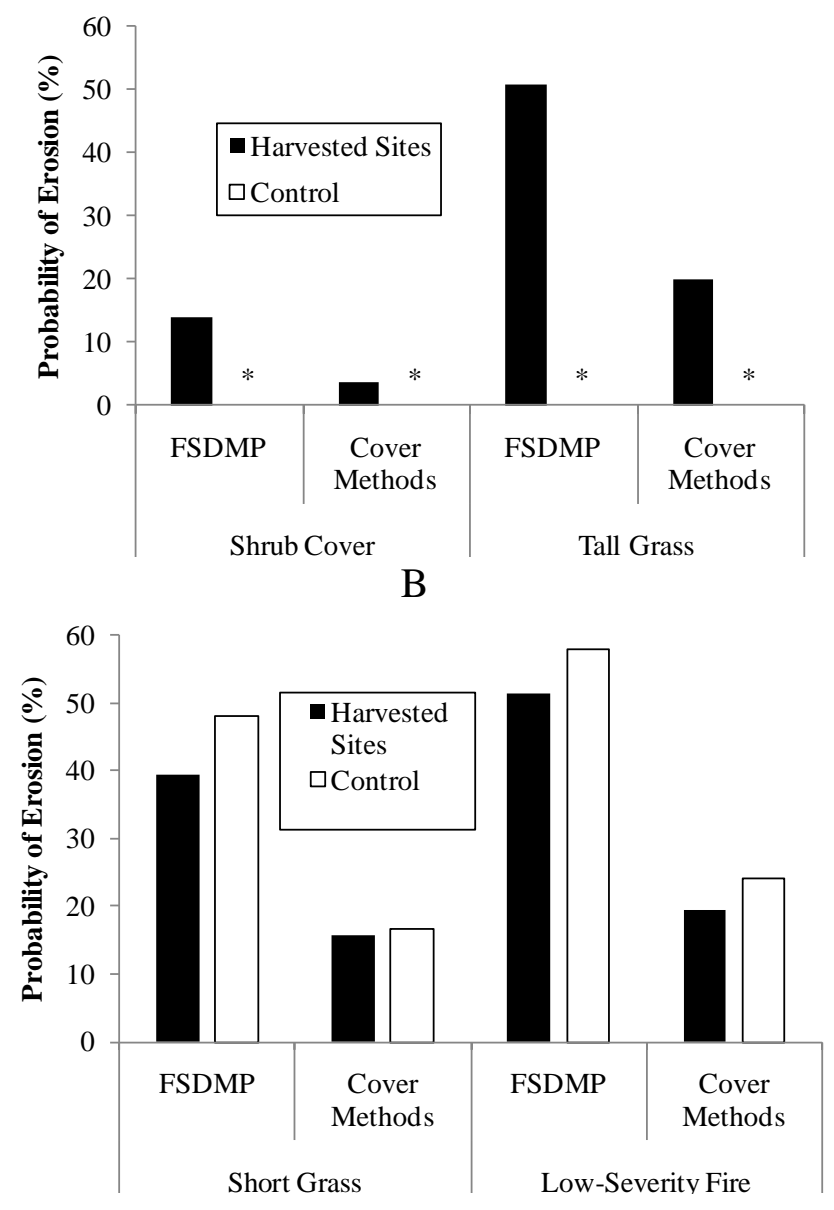

Figure 6. Predicted probability of erosion from FSWEPP Results. For the Carter Mountain site (A), two vegetation condition (treatment) types are shown: Shrub and Tall Grass. *Predicted erosion at the Carter control sites was 0\%. Treatment types for the Purdy site (B) are Short Grass, and Low-Severity Fire. Outputs for the three cover methods were nearly identical and are combined.

Ultimately, the decision of how to use bare soil estimates in the FSWEPP model should be left to individual forest managers. Using accurate inputs into all erosion models is important, but prediction errors associated with the model itself are always high (Elliot, 2000). For example, the FSWEPP erosion predictions were exceptionally low for the Carter Mt. site when data from the cover methods was used with the shrub model treatment (Figure 6A). However, clear evidence of surface erosion, such as rills, 
pedestals, and areas of soil deposition, existed at these sites, possibly indicating field erosion exceeded modeled predictions (Kvamme, unpublished data). Lastly, it should also be noted that FSWEPP only provides predictions for water erosion; wind erosion can also be important when bare soil is exposed, and may be an overriding concern in some areas.

\section{Person-Hour Analysis}

In the FSDMP, there are generally two sampling approaches that result in different time input needs and sample sizes (Page-Dumroese et al., 2009a). If time constraints exist, or if only basic monitoring data are required, a 'Rapid Assessment' can be performed by collecting 30 data points in a timber harvest unit. If more detailed, statistically-backed results are needed, a fixed confidence level (e.g. 80\%) is selected, and an appropriate sample size calculated; this is called the 'Full Assessment' (PageDumroese et al., 2009b). Sampling efficiency data for ground cover variables are presented for both sampling scenarios.

The amount of time needed to collect enough ground cover sample data for the full sampling assessment (at $80 \%$ confidence level) is shown in Figure 7. The $15 \mathrm{~cm}$ plot method was the most efficient, followed by the step-point method. It is surprising that that one of the cover plot methods was more efficient than the FSDMP, because plant canopy studies have shown that frequency estimates are much more efficient than cover percentage (Elzinga et al., 1998). However, many more cover types (plant species) are usually measured in canopy studies than in my ground cover study, which would increase the time required at each plot. 


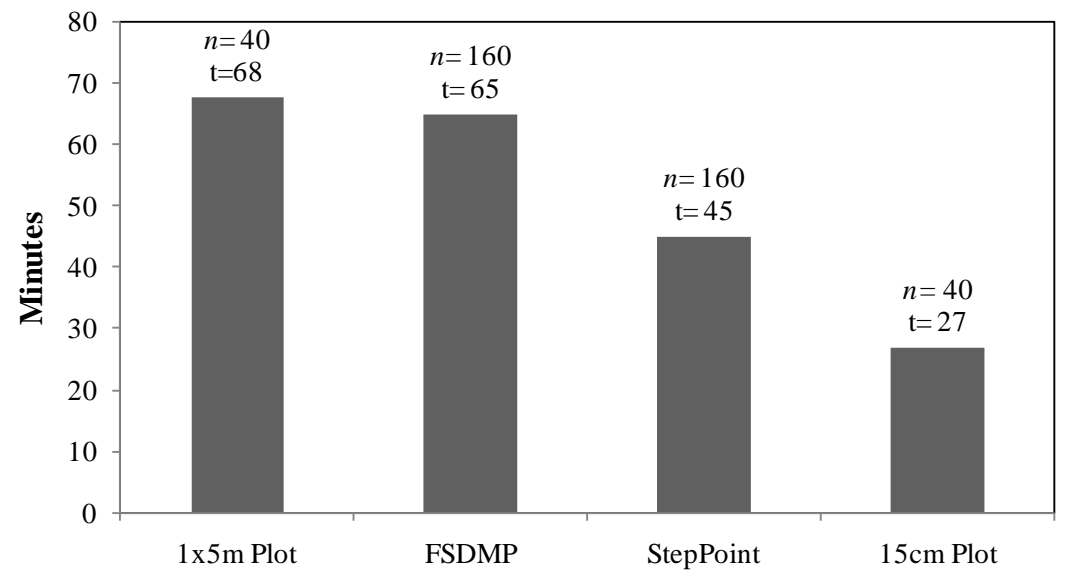

Figure 7. Average sampling time, in minutes, required to meet an $80 \%$ confidence level. $n$ values indicate the average number of samples required per replicate cutting unit. The $t$ values represent the approximate number of minutes required.

Floyd and Anderson (1987) showed that plot-based methods can be the most efficient method when sampling only a single cover type (e.g. shrub canopy), but pointbased methods are the most efficient when multiple cover types are needed, especially at lower sampling intensities. These results agree with my findings for the step-point and large 1 x5m plot, but not for the small $15 \mathrm{~cm}$ dia. plot. However, most other efficiency analyses have been performed on $0.1 \mathrm{~m}^{2}$ or $1 \mathrm{~m}^{2}$ cover plots. In my study, the much smaller $15 \mathrm{~cm}$ diameter circle $\left(\approx .02 \mathrm{~m}^{2}\right)$ was considerably more efficient than the large $5 \mathrm{~m}^{2}$ plot, because it required essentially no set-up time, and assessment was more rapid. When compared to the FSDMP frequency method, the $15 \mathrm{~cm}$ cover plot is more efficient simply based on the smaller sample size required to meet the selected confidence level.

To compare the variability of ground cover estimates at the reduced sample size used in the 'Rapid Assessment' approach, subsamples of the following sizes were taken from the original field data to calculate standard errors (Figure 8). In this approach, it 
A

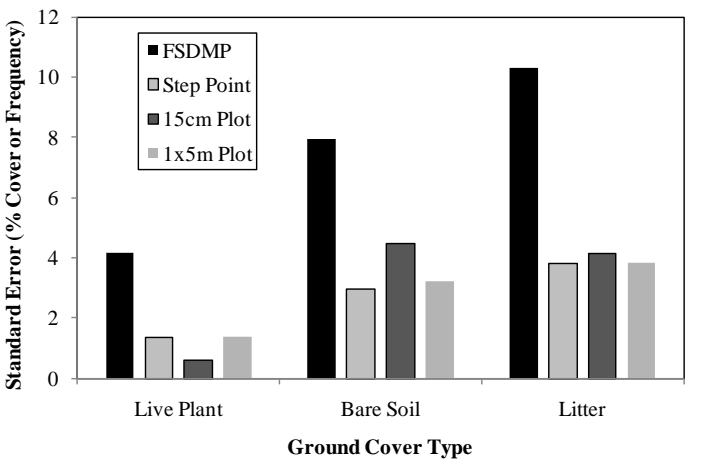

B

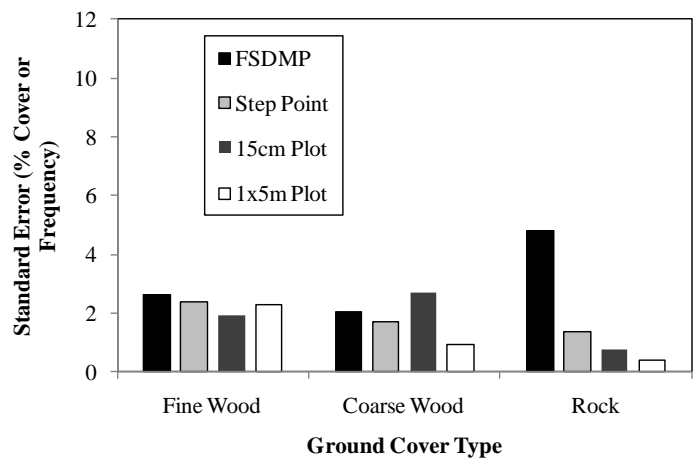

Figure 8. Estimated standard errors of percent cover (or frequency for the FSDMP method) for the 'Rapid Assessment' sampling technique. Sample sizes are: $n=30$ for FSDMP, $n=43$ for step-point, $n=18$ for $15 \mathrm{~cm}$ plot, and $n=7$ for the $1 \times 5 m$ plot.

takes approximately 12 minutes to collect 30 ground frequency points with the FSDMP method. In this same amount of time, 43 step-point measurements could be collected, 18 plots of $15 \mathrm{~cm}$, or $71 \mathrm{x} 5 \mathrm{~m}$ plots.

The rapid assessment FSDMP method has a high standard error for most cover types except fine woody debris, which was surprisingly low. Among the three cover estimate methods, none stands out as having the highest standard error with reduced sample sizes. The step-point method has the lowest bare soil standard error (2.9\%), indicating it may be the most reliable for small sample sizes; however, the differences between the other methods are also small $(<2 \%)$. In addition, when using the step-point method in the Rapid Assessment, the larger sample size will collect information from a greater area (largest spread) within a harvested unit, assuming a line transect is used for all methods.

My results are similar to that of Murphy and Lodge (2002), who found a 4-5 standard error range in visual ground cover estimates when using a $40 \mathrm{x} 40 \mathrm{~cm}$ plot 
( $\mathrm{n}=60$ ). I could not find a similar field comparison for point-based estimates; however, it is not surprising to see similar variability in estimates, since several studies have shown canopy cover predictions between point and visual plot methods to be similar under controlled laboratory settings (Murphy and Lodge, 2002; Booth et al., 2006).

\section{Sampling Implications for Soil Disturbance Monitoring}

The Forest Soil Disturbance Monitoring Protocol uses the same frequency technique to assess other soil disturbance variables (e.g. soil compaction, rutting, etc.). Since I did not compare methods for estimating soil disturbances, it is important to know the potential implications for using FSDMP frequency data to assess these variables. One important difference between the soil disturbance variables in the FSDMP and ground cover is the size of soil disturbances are usually larger than the $15 \mathrm{~cm}$ circle plot area, due to the activity of large mechanical equipment. As seen in Figure 4, frequency values for relatively large objects, like coarse wood, approached values for the cover estimation methods. This was likely caused by large pieces of coarse wood often completely covering the FSDMP plot, so that it was identical to the step-point method. When this occurred, there was no partial coverage or double counting of cover types (counting multiple occurrences as one), making the FSDMP and step-point estimates similar (Greig-Smith, 1983). If the FSDMP plot was not completely covered by a ground cover type or soil disturbance, it overestimated percent cover (Goodall, 1952; Warren-Wilson, 1959; Booth et al., 2006). However, since disturbances, such as soil compaction, are frequently as large or larger in scale than coarse wood, it is possible that the FSDMP 
method provides estimates of disturbance similar to percent cover methods. Further investigation is needed to determine how accurately FSDMP measures soil disturbance.

Another important distinction between ground cover and soil disturbance occurrence is that soil disturbances can be layered, like plant canopy cover, at any given point in space. For example, soil compaction and rutting often occur concurrently. In contrast, ground cover is not layered, and if the primary interest is erosion risk, then soil is either covered or it is not. This layering effect means that sum total of all soil disturbance 'cover’ values can exceed 100\%, just as with plant canopy cover (GreigSmith, 1983). Thus, each layer of disturbance cover percent should be interpreted independently, and the total disturbed area can only be obtained by subtracting the percent of undisturbed sample points from 100\% (ITT, 1999). Consequently, managers should not simply report the sum of all soil disturbance types, as may be the tendency, if the total sum of disturbed areas is less than $100 \%$.

Finally, in my study the step-point method only recorded a single ground cover type at each point. To collect soil disturbance data, the step-point method would need to be modified to record all disturbance types present at the sampling point to obtain layered cover estimates.

\section{Plot-Based Techniques}

Most of the problems with the step-point and FSDMP methods discussed above do not apply to visual plot estimates of cover, since the relative amount of each cover type is recorded directly. These methods also have other traits worth discussing. Plot techniques can have large perimeters that increase edge decision error when determining 
whether to include or exclude a disturbance type. Generally, long narrow plots, such as the $1 \mathrm{x} 5 \mathrm{~m}$ plot, have increased edge decision error compared to circular plots (Elzinga et al., 1998). Therefore, I assume the $1 x 5 \mathrm{~m}$ plot has the most edge decision error of all the methods tested, however it was not quantified in this study.

Plot based techniques do offer one notable benefit over frequency and step-point methods in soil disturbance monitoring. Large plot sizes, such as the $1 \times 55$ plot are much more likely to detect relatively rare objects on a site than are points or smaller plots (Elzinga et al., 1998). This could be potentially beneficial for managers interested in tracking the spread of rare or isolated invasive species after a timber harvest or prescribed fire.

\section{CONCLUSION}

The FSDMP method provides frequency data for estimating ground surface cover. While frequency data do detect differences in ground cover that result from timber management, they only give the presence or absence of cover types, not percent ground cover. Ground cover percentage is more frequently used to describe ground surface condition, and is more intuitive. The three methods used for estimating ground cover percentage differed significantly from the FSDMP method for all cover types except coarse wood. Coarse wood estimates did not differ among methods because large pieces of wood often completely covered the FSDMP plot, creating a similar assessment to the step-point method. Accurate monitoring predictions of ground cover are important for meeting soil quality standards in the U.S. Forest Service, and are also useful for 
understanding and predicting soil erosion processes. Since frequency estimates from the FSDMP overestimated the occurrence of bare soil cover, much larger predictions of water erosion were produced with the Disturbed FSWEPP model.

The $15 \mathrm{~cm}$ dia. plot technique was the most efficient method for sampling ground cover at an 80\% confidence level, and could reduce sampling time from the FSDMP method by approximately 38 minutes per sampled site. When using a low sample size Rapid Assessment, the step-point method produced the lowest standard error of bare soil with a sample size of 43 . Overall, however, no cover estimation method showed a clear advantage with reduced sample sizes.

My study indicates that managers should use a percent ground cover assessment technique, rather than the FSDMP for bare soil and erosion prediction modeling. For estimates of other soil disturbances, such as soil compaction and disturbance classes, the FSDMP method may provide a reasonable estimate of percent disturbance cover, as it did for coarse wood. However, additional research is needed to assess this relationship. 


\section{REFERENCES}

B.C. Ministry of Forests. 2001. Soil Conservation surveys guidebook 2nd ed. In: Forest Practices Code of British Columbia Guidebook. Victoria, B.C.. pp. 63. Accessed from: http://www.for.gov.bc.ca/tasb/legsregs/fpc/fpcguide/soilsurv/ soilconsurv.pdf

Brais, S., 2001. Persistence of soil compaction and effects on seedling growth in northwestern Quebec. Soil Science Society of America Journal 65, 1263-1271.

Burger, J.A., Kelting, D.L., 1999. Using soil quality indicators to assess forest stand management. Forest Ecology and Management 122, 155-166.

Canfield, R.J., 1941. Application of the Line Interception Method in Sampling Range Vegetation. Journal of Forestry 39, 388 - 394.

Craigg, T.L., Howes, S.W., 2007. Assessing Quality in Volcanic Ash Soils. In: PageDumroese, D.S., Miller, R., Mital, J., McDaniel, P., Miller, D. (Eds.), Volcanicash-derived forest soils of the inland northwest: Properties and implications for management and restoration. 9-10 November 2005; Coeur d'Alene, ID. Proceedings RMRS-P-44. U.S. Dept. of Agriculture, Forest Service, Rocky Mountain Research Station, Fort Collins, Colo., p. 220 p.

Curran, M., Maynard, D., Heninger, R., Terry, T., Howes, S., Stone, D., Niemann, T., Miller, R.E., 2007. Elements and rationale for a common approach to assess and report soil disturbance. Forestry Chronicle 83, 852-866.

Curran, M.P., Miller, R.E., Howes, S.W., Maynard, D.G., Terry, T.A., Heninger, R.L., Niemann, T., van Rees, K., Powers, R.F., Schoenholtz, S.H., 2005. Progress towards more uniform assessment and reporting of soil disturbance for operations, research, and sustainability protocols. Forest Ecology and Management 220, 1730.

Edwards, L.M., Burney, J.R., 1991. Sediment concentration of interrill runoff under varying soil, ground cover, soil compaction, and freezing regimes. Journal of Environmental Quality 20, 403-407.

Elliot, W.J., Page-Dumroese, D.S., Robichaud, P.R., 1998. The effect of forest management on erosion and soil productivity. In: Lal, R. (Ed.), Soil Quality and Erosion. St. Lucie Press. Boca Ratan, FL. 195-209.

Elliot, W.J., Hall, D.E., Scheele, D.L., 2000. Technical Documentation: Disturbed WEPP Interface for Disturbed Forest and Range Runoff, Erosion and Sediment Delivery. U.S. Forest Service Rocky Mountain Research Station, and San Dimas Tech. and Development Center. Accessed from: http://forest.moscowfsl.wsu.edu/fswepp/ docs/distweppdoc.html. 
Elzinga, C.L., Salzer, D.W., Willoughby, J.W., Nature Conservancy (U.S.), 1998. Measuring \& monitoring plant populations. Bureau of Land Management Technical Reference 1730-1. Denver, Co. pp. 477.

Evans, R.A., Love, R.M., 1957. The Step-Point Method of Sampling: A Practical Tool in Range Research. Journal of Range Management 10, 208-212.

Floyd, D.A., Anderson, J.E., 1987. A comparison of three methods for estimating plant cover. Journal of Ecology 75, 221.

Gomez, A., Powers, R.F., Singer, M.J., Horwath, W.R., 2002a. N uptake and N status in ponderosa pine as affected by soil compaction and forest floor removal. Plant and Soil 242, 263-275.

Gomez, A., Powers, R.F., Singer, M.J., Horwath, W.R., 2002b. Soil compaction effects on growth of young ponderosa pine following litter removal in California's Sierra Nevada. Soil Science Society of America Journal 66, 1334-1343.

Hatton, T.J., West, N.E., Johnson, P.S., 1986. Relationships of the error associated with ocular estimation and actual total cover. Journal of Range Management 39, 91-92.

Heninger, R., Scott, W., Dobkowski, A., Miller, R., Anderson, H., Duke, S., 2002. Soil disturbance and 10-year growth response of coast Douglas-fir on nontilled and tilled skid trails in the Oregon Cascades. Canadian Journal of Forest ResearchRevue Canadienne De Recherche Forestiere 32, 233-246.

Howes, S., Hazard, J., Geist, J., Region, P., States, U., Service, F., 1983. Guidelines for Sampling Some Physical Conditions of Surface Soils. United States Forest Service, Pacific Northwest Region.

Hutchings, S.S., Holmgren, R.C., 1959. Interpretation of loop-frequency data as a measure of plant cover. Ecology 40, 688 - 677.

Interagency Technical Team (I.T.T.), 1999. Sampling Vegetation Attributes. Bureau of Land Management Technical Reference, 1734-4. Denver, CO. pp. 163.

Jurgensen, M.F., Harvey, A.E., Graham, R.T., Page-Dumroese, D.S., Tonn, J.R., Larsen, M.J., Jain, T.B., 1997. Impacts of timber harvesting on soil organic matter, nitrogen, productivity, and health of Inland Northwest forests. Forest Science 43, 234-251.

Laiho, R., Prescott, C.E., 2004. Decay and nutrient dynamics of coarse woody debris in northern coniferous forests: a synthesis. Canadian Journal of Forest ResearchRevue Canadienne De Recherche Forestiere 34, 763-777.

Lang, R.D., 1979. The effect of ground cover on surface runoff from experimental plots. Journal of the Soil Conservation Service of New South Wales 35, 108 - 114. 
Larsen, I.J., MacDonald, L.H., Brown, E., Rough, D., Welsh, M.J., Pietraszek, J.H., Libohova, Z., Benavides-Solorio, J.D., Schaffrath, K., 2009. Causes of Post-Fire Runoff and Erosion: Water Repellency, Cover, or Soil Sealing? Soil Science Society of America Journal 73, 1393-1407.

Maxwell, W.G.; Ward, F.R. 1980. Photo series for quantifying natural forest residues in common vegetation types of the Pacific Northwest. U.S. Department of Agriculture, Forest Service, Pacific Northwest Forest and Range Experiment Station. Gen. Tech. Rep. PNW-GTR-105. Portland, OR:

Miller, R.E., Scott, W., Hazard, J.W., 1996. Soil compaction and conifer growth after tractor yarding at three coastal Washington locations. Canadian Journal of Forest Research-Revue Canadienne De Recherche Forestiere 26, 225-236.

Ottmar, R.D., Sandberg, D.V., Riccardi, C.L., Prichard, S.J., 2007. An overview of the Fuel Characteristic Classification System - Quantifying, classifying, and creating fuelbeds for resource planning. Canadian Journal of Forest Research-Revue Canadienne De Recherche Forestiere 37, 2383-2393.

Packer, P.E., 1967. Forest treatment effects on water quality. In: Sopper, W.E., Lull, H.H. (Eds.), Proceedings from the International Symposium on Forest Hydrology. Pergammon Press, New York, pp. 687-689.

Page-Dumroese, D.S.; Abbott, Ann M.; Rice, Thomas M. 2009a. Forest Soil Disturbance Monitoring Protocol: Volume I: Rapid assessment. U.S. Department of Agriculture, Forest Service. Gen. Tech. Rep. WO-GTR-82a. Washington, DC: $31 \mathrm{p}$.

Page-Dumroese, D.S.; Abbott, A.M.; Rice, T.M. 2009b. Forest Soil Disturbance Monitoring Protocol: Volume II: Supplementary methods, statistics, and data collection. U.S. Department of Agriculture, Forest Service. Gen. Tech. Rep. WO-GTR-82b. Washington, DC. 64 p..

Page-Dumroese, D.S., Jurgensen, M.F., Elliot, W., Rice, T., Nesser, J., Collins, T., Meurisse, R., 2000. Soil quality standards and guidelines for forest sustainability in northwestern North America. Forest Ecology and Management 138, 445-462.

Page-Dumroese, D.S., Jurgensen, M.F., Tiarks, A.E., Ponder, F., Sanchez, F.G., Fleming, R.L., Kranabetter, J.M., Powers, R.F., Stone, D.M., Elioff, J.D., Scott, D.A., 2006. Soil physical property changes at the North American Long-Term Soil Productivity study sites: 1 and 5 years after compaction. Canadian Journal of Forest Research-Revue Canadienne De Recherche Forestiere 36, 551-564. 
Powers, R., Tiarks, A., Boyle, J., 1998. Assessing Soil Quality: Practicable Standards for Sustainable Forest Productivity in the United States of America. In: Adams, M.B., Davidson, E.A., Ramakrishna, K. (Eds.), The contribution of soil science to the development of and implementation of criteria and indicators of sustainable forest management. SSSA Special Publication No. 53, Madison, WI, pp. 53-80.

Powers, R.F., Alban, D.H., Miller, R.E., Tiarks, A.E., Wells, C.G., Avers, P.E., Cline, R.G., Fitzgerald, R.O., Loftus Jr., N.R., 1990. Sustaining site productivity in North American forests: problems and prospects. In: Gessel, S.P., Lacate, D.S., Weetman, G.F., Powers, R.F. (Eds.), Sustained Productivity of Forest Soils. Proceedings of the Seventh North American Forest Soils Conference. Faculty of Forestry Publication, University of British Columbia, Vancouver, British Columbia, pp. 49 - 79.

Powers, R.F., Scott, D.A., Sanchez, F.G., Voldseth, R.A., Page-Dumroese, D.S., Elioff, J.D., Stone, D.M., 2005. The North American long-term soil productivity experiment: Findings from the first decade of research. Forest Ecology and Management 220, 31-50.

Robichaud, P.R., Luce, C.H., Brown, R.E., 1993. Variation among different surface conditions in timber harvest sites in the southern Appalachians. In: Larionov, G.A., Nearing, M.A. (Eds.), Proceedings of the International Russian, United States, Ukrainian Workshop on Quantitative Assessment of Soil Erosion. The Center for Technology Transfer and Pollution Prevention, Purdue University, Moscow, Russia, pp. 231-241.

Scheaffer, R.L., Mendenhall, W., Ott, R.L., 2006. Elementary survey sampling. 6th ed. Belmont, CA: Thomson Brooks/Cole. 464 pp.

Scott, 2000. A soil disturbance classification system. Internal Report For. Res. Tech. Note, Paper \#00-1. Weyerhaeuser Co., Federal Way, WA. 12 p..

Simanton, J.R., Weltz, M.A., Larsen, H.D., 1991. Rangeland experiments to parameterize the water erosion prediction project model - Vegetation canopy cover effects. Journal of Range Management 44, 276-282.

Soil Survey Staff, 2003. Keys to Soil Taxonomy, 9th ed. United States Department of Agriculture, Natural Resources Conservation Service, Washington, DC, USA, $332 \mathrm{pp}$.

Steel, R.G.D., Torrie, J.H., Dickey, D.A., 1996. Principles and Procedures of Statistics: A Biometrical Approach. $3^{\text {rd }}$ ed. McGraw Hill, New York, USA. 672 pp. 
Swanson, F.J., Clayton, J.L., Megahan, W.F., Bush, G., 1989. Erosional Processes and Long-Term Site Productivity. In: Perry, D.A., Meurisse, R., Thomas, B., Miller, R., Boyle, J., Means, J., Perry, C.R., Powers, R.F. (Eds.), Maintaining the longterm productivity of Pacific Northwest forest ecosystems. Timber Press, Portland, Or., pp. 67 - 81.

Triola, M.F., 2001. Elementary statistics. 8th ed. Upper Saddle River, NJ: Addison Wesley Longman, Inc. 855 pp.

Walker, B.H., 1970. An Evaluation of Eight Methods of Botanical Analysis on Grasslands in Rhodesia. Journal of Applied Ecology 7, 403-416.

Warren-Wilson, J., 1963. Errors Resulting From Thickness of Point Quadrats. Australian Journal of Botany 11, 178-188.

Woldendorp, G., Keenan, R.J., Barry, S., Spencer, R.D., 2004. Analysis of sampling methods for coarse woody debris. Forest Ecology and Management 198, 133-148.

Youngberg, C.T., 1959. The Influence of Soil Conditions, Following Tractor Logging, on the Growth of Planted Douglas-Fir Seedlings. Soil Science Society of America Journal 23, 76-78. 